\title{
Avaliação da casca do fruto e do caule do mandacaru como fontes de compostos fenólicos totais antioxidantes através da obtenção de extratos pelas técnicas de maceração e ultrassom
}

Evaluation of mandacaru fruit peel and stem as sources of total antioxidant phenolic compounds by obtaining extracts by maceration and ultrasound techniques

\author{
G. B. Araújo; L. C. L. de A. Santana* \\ Departamento de Tecnologia de Alimentos, Laboratório de Microbiologia de Alimentos e Bioengenharia, Universidade \\ Federal de Sergipe, 49100-000, Aracaju-Sergipe, Brasil
}

*aquinoluciana@hotmail.com

(Recebido em 11 de junho de 2020; aceito em 29 de agosto de 2020)

\begin{abstract}
O crescente interesse mundial por frutas nativas do Brasil tem incentivado a realização de pesquisas na Caatinga, um bioma puramente brasileiro. Uma das plantas mais típicas do semiárido nordestino é o mandacaru (Cereus jamacaru D.C) da família Cactaceae, que apresenta a capacidade de se desenvolver em condições de extrema limitação hídrica devido à sua morfologia e metabolismo. Neste trabalho, foram obtidos extratos da casca do fruto e caule do mandacaru pelas técnicas de maceração e ultrassom, utilizando os solventes acetona, etanol e metanol, em concentrações que variaram entre 50 e $80 \%$. O extrato da casca do fruto em metanol $60 \%$ obtido por maceração demonstrou maior teor de fenólicos totais $(4.305,6 \mathrm{mg}$ EAG/100g seca da casca). O maior teor de flavonoides totais foi obtido no extrato do caule em acetona $50 \%$ por ultrassom $(370,0 \mathrm{mg}$ QCT/100g seca de caule). Também extratos da casca demonstraram maior capacidade antioxidante do que os extratos do caule, com destaque para extrato em etanol $80 \%$ obtido por maceração. Os extratos do caule e casca do fruto do mandacaru demonstraram potencial para serem utilizados em estudos futuros como antioxidantes naturais.
\end{abstract}

Palavras-chave: fenólicos, flavonoides, caatinga.

The growing worldwide interest in Brazilian native fruits has encouraged research in the Caatinga, a purely Brazilian biome. One of the most typical plants of the northeastern semiarid is the mandacaru (Cereus jamacaru D.C) of Cactaceae family, which has the ability to develop in conditions of extreme water limitation due to its morphology and metabolism. In this work, extracts of peel of fruit and stem of the mandacaru were obtained by maceration and ultrasound techniques, using the solvents acetone, ethanol and methanol, in concentrations that varied between 50 and $80 \%$. The fruit peel extract in methanol $60 \%$ obtained by maceration showed a higher content of total phenolics $(4,305.6 \mathrm{mg} \mathrm{GAE} / 100 \mathrm{~g}$ dry peel). The highest content of total flavonoids was obtained in the stem extract in $50 \%$ acetone by ultrasound $(370.0 \mathrm{mg}$ QCT/100g dry stem). Peel extracts also showed greater antioxidant capacity than stem ones, with an emphasis on $80 \%$ ethanol extract obtained by maceration. The extracts from the stem and peel of the mandacaru fruit demonstrated the potential to be used in future studies as natural antioxidants.

Keywords: phenolic, flavonoid, caatinga.

\section{INTRODUÇÃO}

O Brasil possui um grande número de espécies frutíferas nativas e exóticas, potencialmente interessantes na agroindústria e podem gerar desenvolvimento econômico e social [1]. O país é o terceiro maior produtor de frutas no mundo, com um volume de produção superior a 40 milhões de toneladas, o que representa no mercado externo $5,7 \%$ da produção mundial [2].

O mandacaru (Cereus jamacaru D.C) pertence ao gênero Cereus, que possui aproximadamente 34 espécies, pertence à família Cactaceae e subfamília Cactoideae. As espécies deste gênero são de porte a arbustivo-arbóreo, plantas de hábito de crescimento colunar e caule com conformação angular, flores brancas e cresce junto a solos pedregosos, crescendo em torno de 3 a 7 metros. Sendo uma espécie nativa de Caatinga, está bem adaptada às condições semiáridas do nordeste brasileiro e é típico em toda a região. Em longos períodos de seca, é empregado como fonte de água 
e alimento para ruminantes e aves. Sua madeira é utilizada na construção, para fazer portas, tábuas e ripas [3-5].

O uso medicinal do mandacaru é pouco disseminado, mas popularmente são utilizados suas raízes e caule para ação diurética, doenças cardiovasculares, respiratórias e renais, e também no combate ao escorbuto [6]. As raízes podem ser utilizadas em forma de chá, no tratamento de reumatismo, feridas, furúnculos, infecções urinárias [7]. Alguns pesquisadores têm avaliado propriedades farmacológicas e foi verificado que o caule do mandacaru promove atividade anticitotóxica e antitumoral [8] sem gerar efeitos tóxicos e nem alterações nos parâmetros bioquímicos e hematológicos estudados [9]. Foi observado também nesses extratos vegetais um potencial anticolinesterásico em doenças neurodegenerativas, como doença de Alzheimer [10]. Os frutos ainda não são comercializados, contudo podem ser consumidos de forma natural ou na preparação de doces e geleias [11]. Os frutos de cactos também possuem potencial uso como corante natural de alimentos, devido a presença de altas concentrações de betalaína [12].

Ao longo dos anos pesquisadores têm demonstrado que partes de plantas e resíduos agroindustriais de frutas como casca e sementes são ricos em compostos bioativos, sobretudo polifenóis, com elevado potencial antioxidante [13]. A atividade antioxidante se deve principalmente às suas propriedades de óxido redução, pela transferência de hidrogênio que neutraliza a ação de radicais livres [14]. Compostos fenólicos antioxidantes possuem diversos de benefícios à saúde, na prevenção de doenças neurológicas, câncer, diabetes, doenças cardiovasculares, obesidade, entre outras $[15,16]$.

Para a extração de compostos bioativos de plantas a maceração tem sido considerado o principal método utilizado ao longo dos anos. É um método simples, que requer aparelhos relativamente de baixo custo e resultam em altas taxas de extração. Porém há algumas desvantagens, como o uso de uma grande demanda de solventes orgânicos que podem ocasionar riscos à saúde e poluição ambiental, longos períodos de extração para se alcançar o rendimento máximo dos compostos de interesse, degradação térmica e reações enzimáticas [17]. Métodos alternativos tem sido propostos como a extração assistida por ultrassom, a qual consiste em ondas ultrassônicas para facilitar a extração de compostos utilizando solventes líquidos, numa frequência superior a $20 \mathrm{kHz}$, essas ondas mecânicas causam uma pressão negativa no solvente e a formação de pequenas bolhas ocorrem, essas bolhas colapsam resultando na formação de cavitação [18]. As duas formas mais comuns de extração assistida por ultrassom, são os sistemas de banho e sonda ultrassônica. O banho ultrassônico, permite maior reprodutibilidade e atuam em uma variedade de amostras ao mesmo tempo, entretanto a sonda atua diretamente na amostra podendo causar o risco de contaminação e difícil reprodutibilidade [19]. A extração assistida por ultrassom é um método rápido, que melhora a qualidade e a produtividade do processo [20]. Diante do exposto, o presente trabalho objetivou determinar os teores de compostos bioativos e a atividade antioxidante in vitro de extratos obtidos a partir da casca do fruto e do caule do mandacaru utilizando as técnicas de maceração e ultrassom, ainda não utilizadas para esta finalidade.

\section{MATERIAL E MÉTODOS}

\subsection{Material}

Os frutos $(3,0 \mathrm{~kg})$ e o caule $(1,5 \mathrm{~kg})$ do mandacaru foram coletados em propriedades rurais, localizadas no município de Antas/BA. A triagem das frutas foi realizada visualmente e sua seleção foi através da sua coloração vermelha, no estádio de maturação maduro. Álcool absoluto 99,8\% P.A e acetona P.A foram adquiridos da Neon Comercial (Suzano, Brasil). Álcool metílico P.A foi adquirido da Vetec Química Fina LTDA (Rio de Janeiro, Brasil). Carbonato de sódio anidro P.A e cloreto de alumínio P.A foram adquiridos da Dinâmica (Indaiatuba, Brasil). Os reagentes Folin Ciocalteau, Trolox (6-hidroxi-2,5,7,8-tetrametilcromo-2-ácido carboxílico), DPPH (2,2-difenil-1picrilhydrazil), ABTS (2'-Azino-bis(3-ethilbenzothiazoline-6-ácido sulfônico) e FRAP (poder redutor do ferro) foram obtidos da Sigma-Aldrich (MO, EUA). 


\subsection{Obtenção da farinha da casca do fruto e do caule do mandacaru}

Os frutos e o caule foram higienizados em água corrente para retirada de impurezas e em seguida foram imersos em solução clorada a 200ppm por $15 \mathrm{~min}$. As cascas foram separadas manualmente dos frutos. A casca e o caule foram secos em estufa a $50^{\circ} \mathrm{C}$ por $24 \mathrm{~h}$ e em seguida triturados em liquidificador [21].

\subsection{Obtenção dos extratos da casca do fruto e do caule do mandacaru}

Para a obtenção dos extratos ( $25 \mathrm{~mL}$ ), $5 \mathrm{~g}$ de farinha (da casca ou do caule do mandacaru) foram misturadas com $25 \mathrm{~mL}$ de solvente em Erlenemyers de $125 \mathrm{~mL}$. Os solventes utilizados foram soluções de metanol, etanol e acetona em água destilada nas concentrações de 50\%, 60\% 70\% e $80 \%$ (v/v) [21]. Para a extração por maceração os Erlemeyers foram colocados em agitação orbital a 200rpm, temperatura de $30^{\circ} \mathrm{C}$ durante $1 \mathrm{~h}$ no equipamento tipo "shaker" (modelo TE-420, Tecnal, Brasil) [21] e para extração por ultrassom utilizou-se $50 \mathrm{kHz}$ de frequência e $250 \mathrm{VA}$ de potência, em banho aquecido a $30^{\circ} \mathrm{C}$, por $1 \mathrm{~h}$, utilizando banho ultrassonico modelo USC-1400 (Unique, Brasil) [22]. Após o tempo, os extratos obtidos em cada técnica foram filtrados em papel filtro e os sobrenadantes utilizados para as análises subsequentes. Para o cálculo de rendimento de extração os extratos foram rotaevaporados e determinada a massa obtida. O rendimento foi expresso em $\mathrm{g}$ de extrato rotaevaporado por $\mathrm{g}$ de farinha da casca do fruto ou do caule do mandacaru multiplicado por 100 .

\subsection{Determinação de fenólicos totais}

Os ensaios do teor de compostos fenólicos totais foram determinados pelo método de FolinCiocalteau, utilizando ácido gálico como padrão de referência [23]. Para a quantificação de fenóis nas amostras, foi retirado $1 \mathrm{~mL}$ do extrato diluído e transferidos para tubos de ensaio em triplicata, adicionando-se em sequência, $1 \mathrm{~mL}$ de etanol a $95 \%, 5 \mathrm{~mL}$ de água destilada e $0,5 \mathrm{~mL}$ de solução Folin-Ciocalteau (1N), seguido de homogeneização. Em seguida, adicionou-se $1 \mathrm{~mL}$ de solução de carbonato de sódio a $5 \%(\mathrm{p} / \mathrm{v})$, seguindo-se de nova homogeneização em vórtex, formando uma mistura de cor azul. A solução foi deixada em repouso em ambiente escuro por $1 \mathrm{~h}$. Após este tempo foi lida a absorbância a $725 \mathrm{~nm}$ em espectrofotômetro (Spectrum SP 2000UV). O mesmo procedimento foi realizado substituindo a amostra pelo solvente, para obtenção do branco.

Para a quantificação dos compostos, construiu-se uma curva de calibração construída a partir de diferentes concentrações de ácido gálico $(0-150 \mathrm{mg} / \mathrm{L})$, a fim de converter as absorbâncias e expressar os resultados em termos de miligramas de ácido gálico equivalente (EAG) por $100 \mathrm{~g}$ de farinha seca (mg EAG/100 g seca da casca do fruto ou caule do mandacaru).

\subsection{Determinação de flavonoides totais}

A quantificação de flavonoides totais foi determinada conforme método de Meda et al. (2005) [24], com algumas modificações. $O$ teor de flavonoides totais foi determinado através da curva de calibração de quercetina. Alíquotas de $2 \mathrm{~mL}$ de extrato diluídos foram colocadas em tubos de ensaio e adicionou-se de $2 \mathrm{~mL}$ de cloreto de alumínio $2 \%$ (p/v), seguindo de homogeneização em vortex, mantendo-se em repouso em ambiente escuro por 30 min. As absorbâncias das amostras foram lidas à $415 \mathrm{~nm}$. O mesmo procedimento foi realizado substituindo a amostra pelo solvente para obtenção do branco. A concentração total de flavonoides totais foi determinada através de uma curva de calibração construída a partir de diferentes concentrações de quercetina (0-100 mg/L). Os resultados foram convertidos e expressos em termos de miligramas de quercetina (QCT) por $100 \mathrm{~g}$ de peso seco de resíduo (mg QCT/100g seca de casca do fruto ou caule do mandacaru).

\subsection{Atividade antioxidante}


Os extratos que demonstraram maiores teores de fenólicos totais e flavonoides totais foram analisados quanto a atividade antioxidante (AA) in vitro utilizando-se os métodos DPPH (2,2difenil-1-picrilhydrazil) [25], ABTS (2'-Azino-bis(3-ethilbenzothiazoline-6-ácido sulfônico) [26] e FRAP (Ferric Reducing Antioxidant Power) [27]. Para o método DPPH, misturou-se $250 \mu \mathrm{L}$ do extrato diluído à $1,25 \mathrm{~mL}$ de DPPH, em triplicata. Após $5 \mathrm{~min}$, realizou-se a leitura da absorbância a $517 \mathrm{~nm}$ no espectrofotômetro. Diferentes concentrações de Trolox variando de 50 a $250 \mu \mathrm{mol}$ Trolox/L foram utilizados para construção da curva de calibração, onde os resultados foram expressos em $\mu \mathrm{mol}$ Trolox/g seca de casca ou caule. O branco foi realizado substituindo o extrato por etanol. O método ABTS for realizado misturando-se em tubos de ensaio $30 \mu \mathrm{L}$ de extrato diluído à $3 \mathrm{~mL}$ do radical ABTS + em triplicata, sendo homogeneizados em vórtex. Após 6 min, realizou-se a leitura do valor de absorbância a $734 \mathrm{~nm}$. Diferentes concentrações de Trolox (entre 100 e $1600 \mu \mathrm{mol}$ Trolox/L) foram utilizadas para construir a curva de calibração. Os resultados foram expressos $\mu \mathrm{mol}$ de Trolox/g seca de casca ou caule. O etanol foi utilizado como branco. No método FRAP, $90 \mu \mathrm{L}$ do extrato diluído foi transferido para tubos de ensaio, em triplicata, contendo $70 \mu \mathrm{L}$ de água destilada e $2,7 \mathrm{~mL}$ do reagente FRAP. Os tubos foram homogeneizados em vórtex e mantidos a $37^{\circ} \mathrm{C}$ em banho-maria. Após $30 \mathrm{~min}$ realizou-se a leitura em um espectrofotômetro a $595 \mathrm{~nm}$. A curva de calibração foi obtida com diferentes concentrações de Trolox (entre 100 e $1200 \mu \mathrm{mol}$ Trolox/L) e os resultados foram expressos em $\mu \mathrm{mol}$ Trolox/g seca de casca ou caule. O branco foi realizado substituindo o extrato por etanol.

\subsection{Análise estatística}

Os resultados foram expressos com média \pm desvio padrão e os valores obtidos nos diferentes solventes em cada técnica separadamente (maceração ou ultrassom) foram comparados através de teste de Tukey ao nível de 5\% de significância utilizando-se o programa Sisvar [21].

\section{RESULTADOS E DISCUSSÃO}

\subsection{Determinação de compostos fenólicos totais e flavonoides totais}

Os rendimentos de extração da casca do fruto e do caule do mandacaru foram em torno de $40 \%$. Os extratos da casca do fruto em metanol 60\% (4.305,6 mg EAG/100g seca de casca), etanol 50\% (4.224,0 mg EAG/100g seca de casca) e metanol 80\% (4.097,7 mg EAG/100g seca de casca) demonstraram os maiores teores de fenólicos totais, não diferindo estatisticamente entre si $(p<0,05)$ (Figura 1). Quando utilizada a técnica de ultrassom, a maior extração de fenólicos totais foi obtida com etanol 50\% (2.600,0 mg EAG/100g seca de casca), diferindo estatisticamente dos demais extratos $(\mathrm{p}>0,05)$. A ordem de polaridade dos solventes do mais polar para o menos polar foi metanol>etanol>acetona [28]. Considerando que o metanol 60 e $70 \%$ e etanol $50 \%$ foram os solventes mais eficientes para extração dos compostos fenólicos, isto significou que a casca do mandacaru demonstrou a presença de compostos moderadamente polares com afinidade para estes solventes. Por outro lado, a menor extração de compostos fenólicos totais obtida pela técnica de ultrassom pode ser devido a uma degradação oxidativa destes compostos induzida pela sonicação [29]. O fenômeno da cavitação leva a altas forças de cisalhamento, essas forças resultam em oscilação e colapso da bolha de cavitação dentro do fluido, ou seja, diferenças de composição (matriz) resultarão em diferentes graus de impacto da cavitação, como fragmentação, erosão, capilaridade, detexturação [30].

Pouco pesquisadores têm obtido compostos bioativos do mandacaru, Calado et al. (2016) [31] obtiveram 400,0 mg EAG/100g massa fresca em extrato da casca do fruto do mandacaru obtido através de um multiprocessador de alimentos modelo (RI7632 650W) sem a utilização de solventes orgânicos. Este resultado foi inferior ao obtido no presente trabalho, cujo valor máximo de extração foi obtido por maceração em metanol $60 \%$ sendo de 3.962,14 mg EAG/100 g de casca do fruto do mandacaru expresso em massa úmida. Melo et al. (2017) [32] realizaram a extração de fenólicos totais em polpa do fruto mandacaru maduro com metanol $50 \%$ mantendo em repouso por $1 \mathrm{~h}$, 
separando o sobrenadante, seguido pela extração do resíduo com acetona $70 \%$ mantendo em repouso por $1 \mathrm{~h}$, e obtiveram 223,22 mg EAG/100 g massa fresca; Moreira et al. (2018) [33] obtiveram $252,3 \mathrm{mg}$ EAG/ $100 \mathrm{~g}$ no extrato aquoso da polpa de mandacaru seca à $40^{\circ} \mathrm{C}$ mantido em repouso por $1 \mathrm{~h}$. Também os valores encontrados na polpa de mandacaru por estes pesquisadores foram inferiores aos encontrados no presente trabalho na casca do fruto do mandacaru.

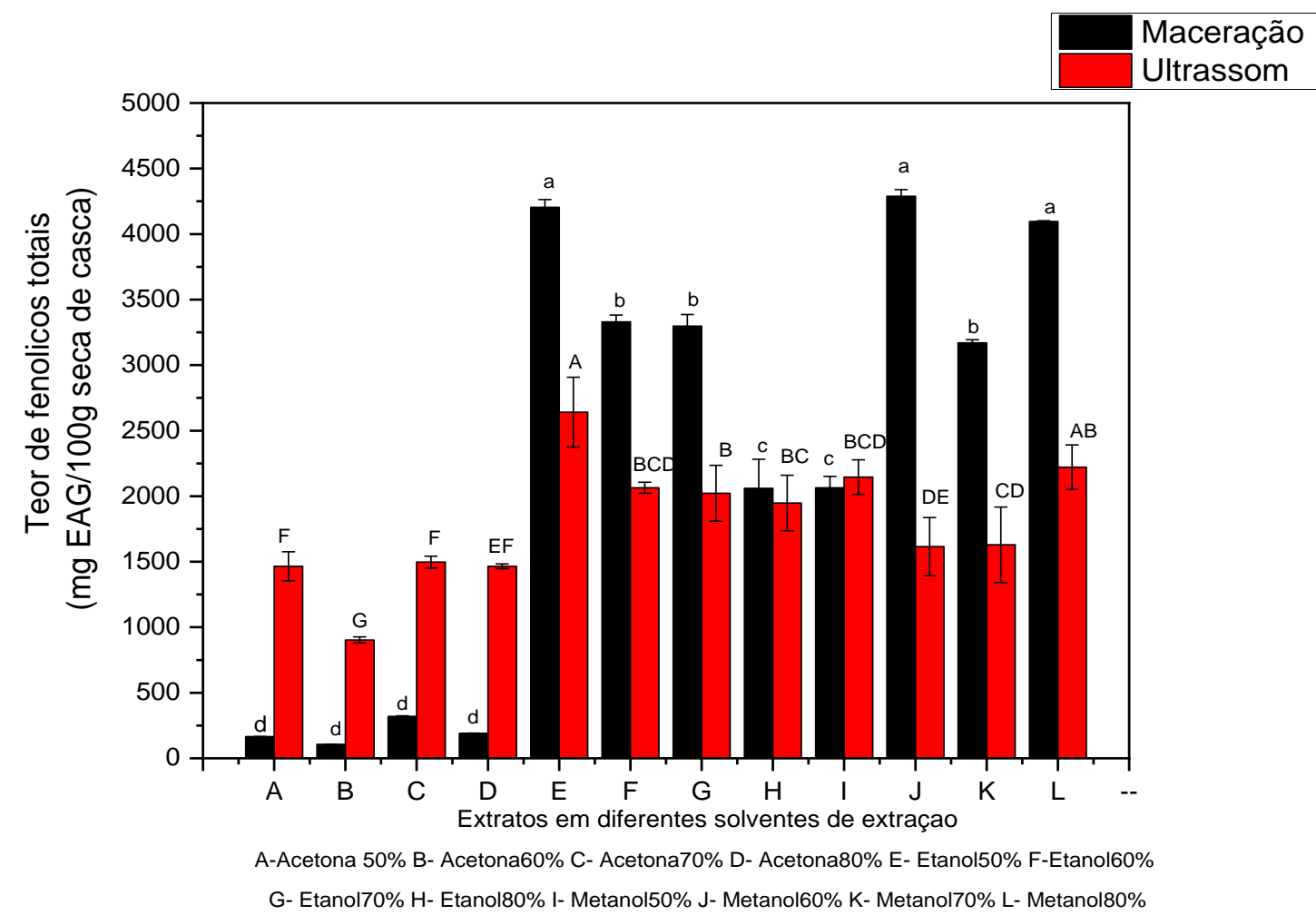

Figura 1: Teores de fenólicos totais (média e desvio padrão) nos extratos da casca do fruto do mandacaru. Letras iguais indicam que as amostras não diferiram entre si $(p<0,05)$ e letras diferentes indicam que diferiram $(p>0,05)$ entre os valores médios do teor de compostos fenólicos totais nos extratos, obtidos por cada técnica separadamente, de acordo com o teste de Tukey. As letras minúsculas são para os valores obtidos pelo método de maceração e as letras maiúsculas são para os valores obtidos por ultrassom.

Já os maiores teores de fenólicos totais do caule do mandacaru foram obtidos nos extratos em acetona $50 \%$ por ultrassom $(787,3 \mathrm{mg}$ EAG/100g seca de caule) e metanol $50 \%$ por maceração (772,0 mg EAG/100g seca de caule) (Figura 2), os quais diferiram estatisticamente dos demais extratos ( $p>0,05)$. Isto significou que por ultrassom foram extraídos compostos mais polares com afinidade pela acetona e por maceração foram obtidos compostos menos polares com afinidade pelo metanol. No entanto os valores destes compostos no caule foram inferiores aos obtidos na casca do fruto. Por outro lado, Wit et al. (2019) [34] verificaram que os teores de fenólicos totais foram maiores no caule e semente dos cactos palma e opúncia do que os obtidos nos seus frutos.

Segundo Silva et al. (2014) [35], os quais classificaram o teor de polifenóis em frutas de regiões tropicais em categorias como: baixo ( $<500 \mathrm{mg}$ EAG/100 g em seca), médio (500-2500 mg EAG/100 g em base seca) e alto (> $2500 \mathrm{mg}$ de EAG/100 $\mathrm{g}$ em base seca), a casca do mandacaru se enquadra na categoria de alto teor de fenólicos totais e o caule na categoria de médio teor destes compostos. 


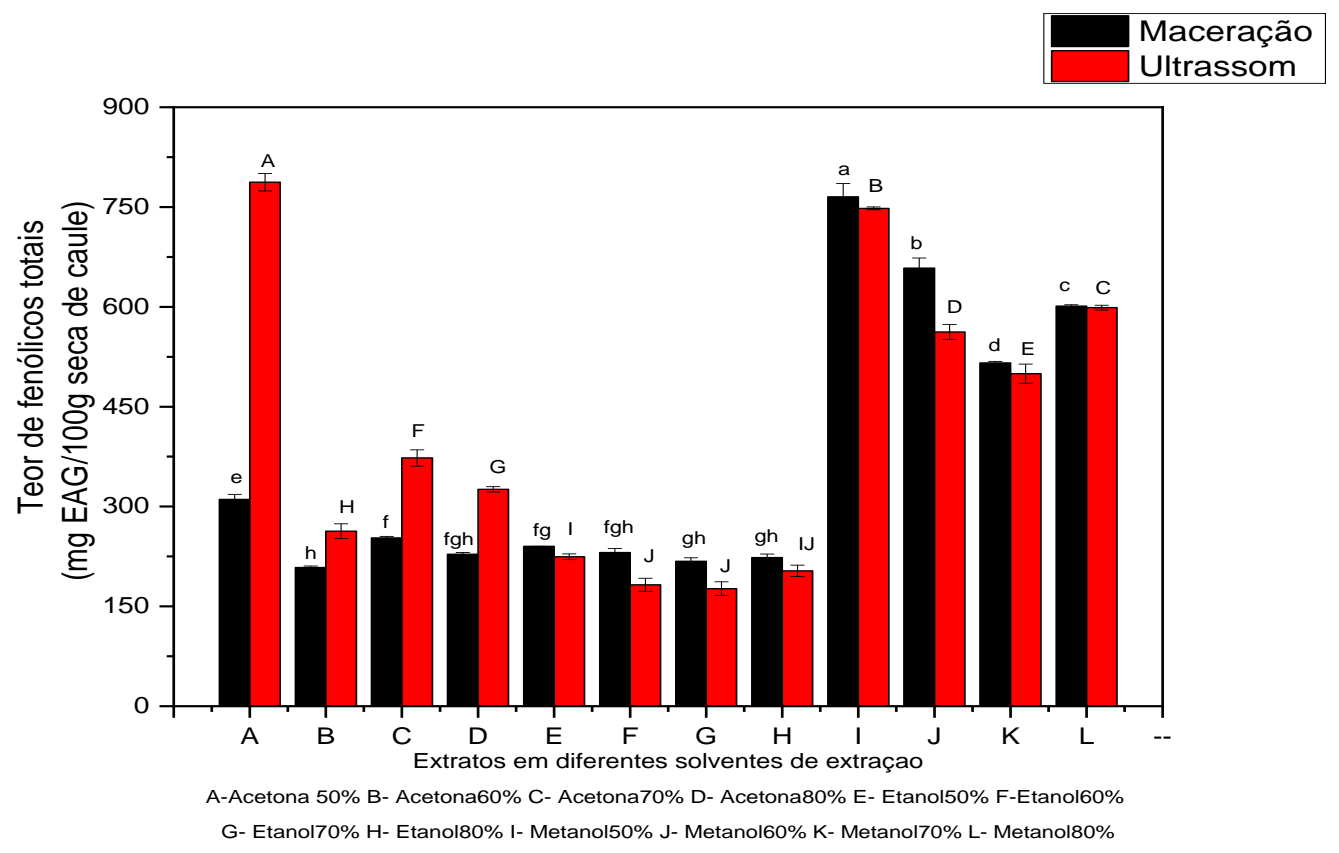

Figura 2: Teores de fenólicos totais (média e desvio padrão) nos extratos do caule do mandacaru. Letras iguais indicam que as amostras não diferiram entre si $(p<0,05)$ e letras diferentes indicam que diferiram $(p>0,05)$ entre os valores médios do teor de compostos fenólicos totais nos extratos, obtidos por cada técnica separadamente, de acordo com o teste de Tukey. As letras minúsculas são para os valores obtidos pelo método de maceração e as letras maiúsculas são para os valores obtidos por ultrassom.

Já os maiores teores de flavonoides totais na casca do fruto foram obtidos nos extratos em etanol $80 \%$ por maceração $(134,0 \mathrm{mg}$ QCT/100g seca de casca) e ultrassom $(132,8 \mathrm{mg}$ QCT/100g seca de casca) e no extrato em acetona $80 \%$, obtido por ultrassom (130,3 mg QCT/100g seca de casca), os quais não diferiram estatisticamente entre si $(\mathrm{p}<0,05)$ (Figura 3). Este resultado significou que pela técnica de maceração foram extraídos compostos menos polares com afinidade pelo etanol $80 \%$. Já pela técnica de ultrassom foram extraídos compostos mais polares com afinidade pela acetone $80 \%$ e menos polares com afinidade pelo etanol $80 \%$. No caule, maior extração de flavonoides totais foi obtida em acetona $80 \%$ tanto pela técnica de ultrassom (200,0 mg QCT/100g seca de caule) como de maceração (370,0 mg QCT/100g seca de caule), diferindo estatisticamente dos demais extratos $(\mathrm{p}>0,05)$ (Figura 4). Isto significou que no caule estes compostos possuem características polares com afinidade pela acetona. 


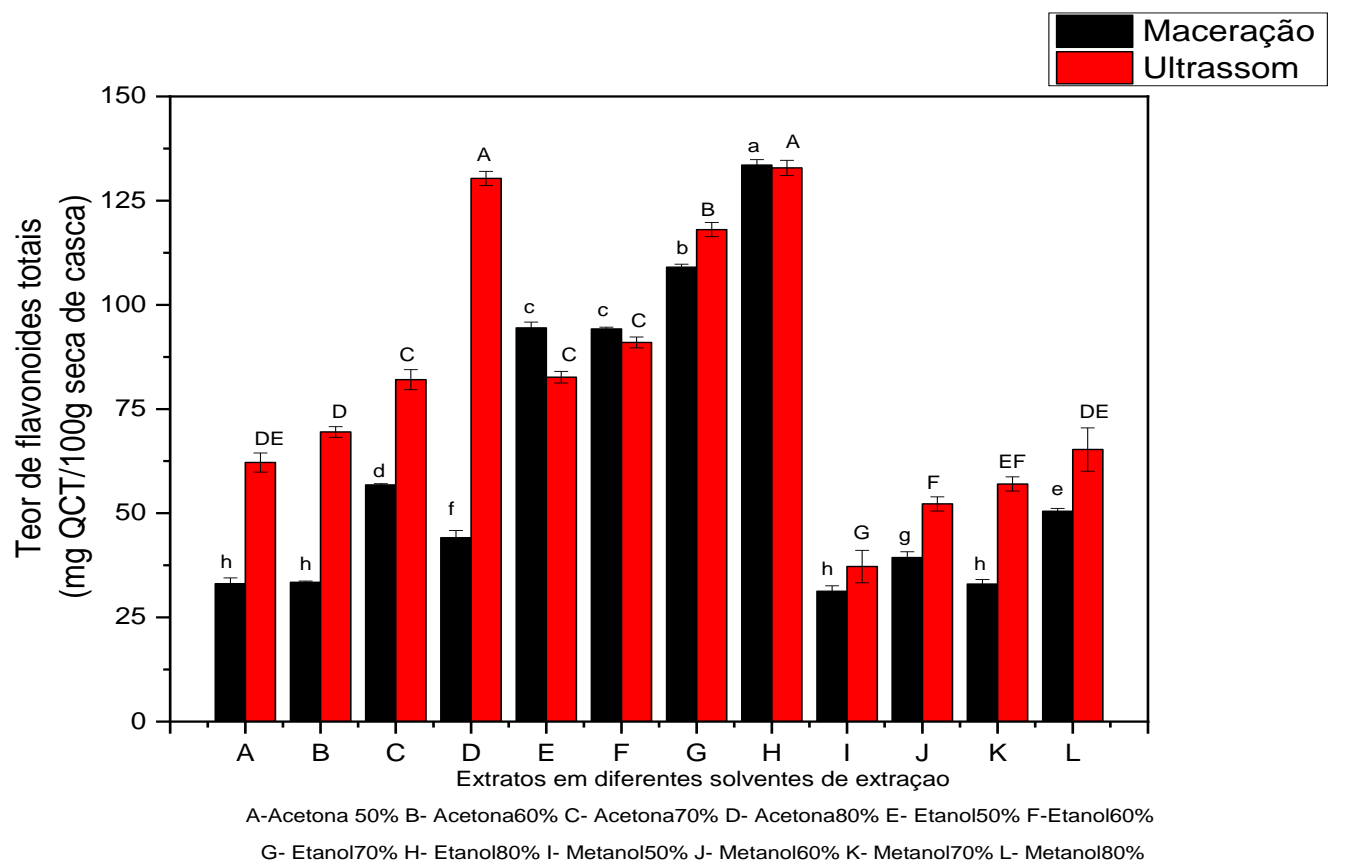

Figura 3: Teores de flavonoides totais (média e desvio padrão) nos extratos da casca do fruto do mandacaru. Letras iguais indicam que as amostras não diferiram entre si $(p<0,05)$ e letras diferentes indicam que diferiram $(p>0,05)$ entre os valores médios do teor de compostos flavonoides totais nos extratos, obtidos por cada técnica separadamente, de acordo com o teste de Tukey. As letras minúsculas são para os valores obtidos pelo método de maceração e as letras maiúsculas são para os valores obtidos por ultrassom.

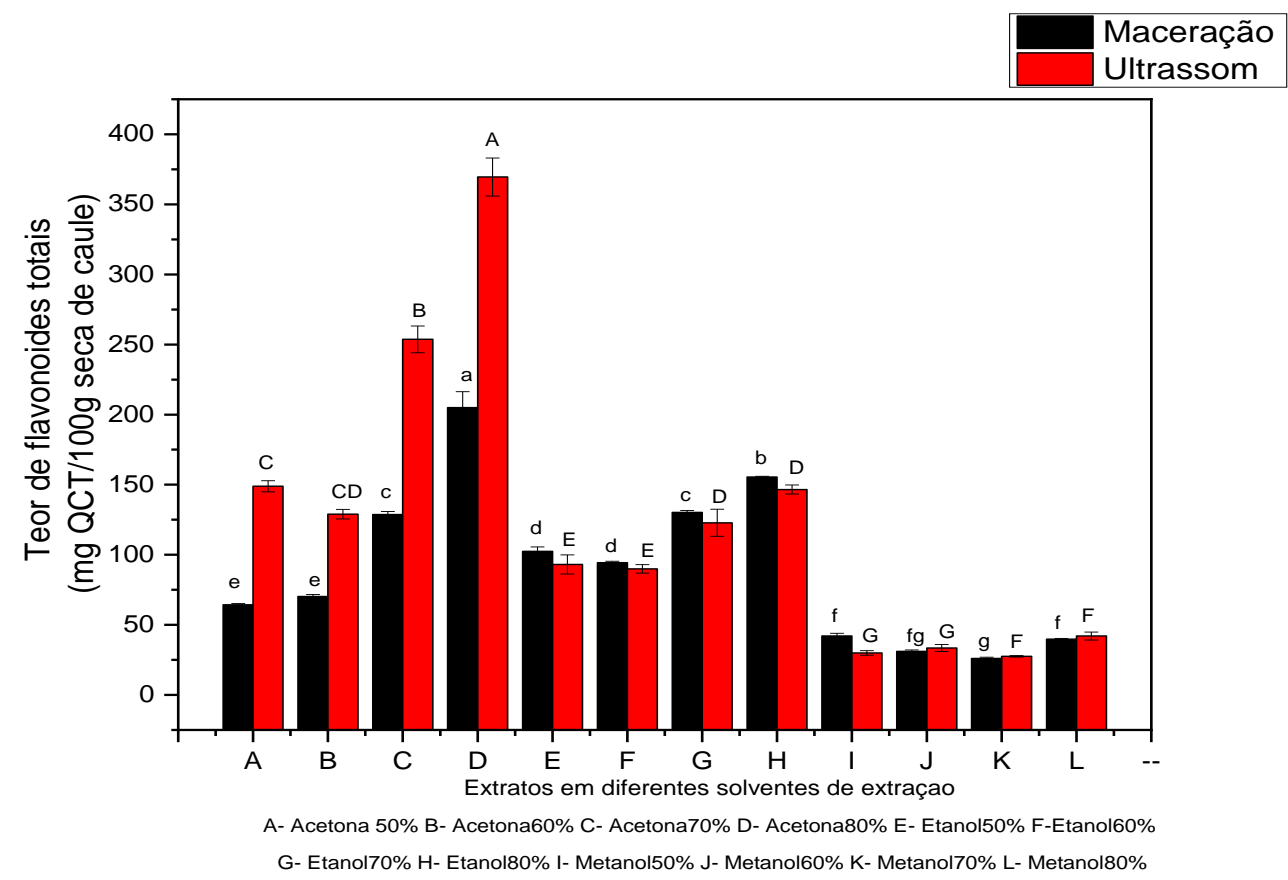

Figura 4: Teores de flavonoides totais( média e desvio padrão) nos extratos do caule do mandacaru. Letras iguais indicam que as amostras não diferiram entre si $(p<0,05)$ e letras diferentes indicam que diferiram $(p>0,05)$ entre os valores médios do teor de compostos flavonoides totais nos extratos, obtidos por cada técnica separadamente, de acordo com o teste de Tukey. As letras minúsculas são para os valores obtidos pelo método de maceração e as letras maiúsculas são para os valores obtidos por ultrassom. 


\subsection{Atividade antioxidante}

A atividade antioxidante in vitro foi realizada para os seguintes extratos da casca do fruto: etanol $50 \%$ pela técnica de maceração (maior teor de fenólicos totais), metanol $60 \%$ pela técnica de maceração (maior teor de fenólicos totais), etanol 50\% pela técnica de ultrassom (maior teor de fenólicos totais), etanol $80 \%$ pela técnica de maceração (maior teor de flavonoides totais), etanol $80 \%$ pela técnica de ultrassom (maior teor de flavonoides totais), acetona $80 \%$ pela técnica de ultrassom (maior teor de flavonoides totais). Considerando que não houve diferença significativa no teor de fenólicos totais para os extratos em etanol 50\%, metanol $60 \%$ e metanol $80 \%$ obtidos por maceração, o extrato em metanol $80 \%$ não foi analisado por ser considerado o mais tóxico dentre os demais. Para os extratos do caule foram analisados os extratos: metanol 50\% obtido por maceração (maior teor de fenólicos totais), acetona 50\% por ultrassom (maior teor de fenólicos totais) e acetona $80 \%$ obtido por maceração (maior teor de fenólicos totais e flavonoides totais).

O extrato da casca em etanol $80 \%$ obtido por maceração demonstrou maior atividade antioxidante pelos métodos ABTS e FRAP diferindo estatisticamente da AA dos demais extratos $(\mathrm{p}>0,05)$ (Tabela 1). Também pelo método DPPH maior AA foi observada no extrato em etanol $80 \%$ obtido por maceração, o qual não diferiu estatisticamente do extrato em etanol $80 \%$ obtido por ultrassom ( $\mathrm{p}<0,05)$. Dutra et al. (2019) [36] também têm obtido maior AA pelos métodos DPPH e ABTS, para o extrato de casca do fruto do mandacaru. Os maiores valores de AA para os extratos de caule foram obtidos pelo método DPPH, no entanto os extratos de casca de fruto demonstraram maior potencial antioxidante do que os extratos do caule do mandacaru. Tanto para o caule como casca do fruto, a maior AA foi obtida nos extratos onde obteve-se maior teor de flavonoides totais, sendo, portanto, estes compostos os responsáveis pelo potencial antioxidante destas partes do mandacaru. Moussa-ayoub et al. (2014) [37] têm associado os flavonoides como os polifenólicos antioxidantes mais importantes presentes em cultivares de palma. Andreu et al. (2018) [38] também obtiveram maior atividade antioxidante na casca do fruto do cacto palma cultivado na Espanha do que no caule.

Tabela 1: Atividade antioxidante dos extratos da casca do fruto e do caule do mandacaru.

Atividade Antioxidante ( $\mu \mathrm{M}$ de Trolox/g seca)

\begin{tabular}{|c|c|c|c|c|c|}
\hline & $\begin{array}{c}\text { Método de } \\
\text { extração }\end{array}$ & Solventes & ABTS & DPPH & FRAP \\
\hline \multirow{5}{*}{$\begin{array}{l}\text { Casca do } \\
\text { fruto }\end{array}$} & \multirow{3}{*}{ Maceração } & Etanol 50\% & $221,50 \pm 3,54^{b}$ & $209,26 \pm 0,49^{\mathrm{d}}$ & $247,00 \pm 0,31^{\mathrm{c}}$ \\
\hline & & Etanol $80 \%$ & $288,58 \pm 3,12^{a}$ & $216,78 \pm 0,78^{\mathrm{a}}$ & $287,31 \pm 0,31^{\mathrm{a}}$ \\
\hline & & Metanol $60 \%$ & $106,92 \pm 0,59^{c}$ & $215,38 \pm 0,43^{b}$ & $128,88 \pm 0,94^{\mathrm{f}}$ \\
\hline & \multirow{3}{*}{ Ultrassom } & Acetona $80 \%$ & $81,08 \pm 1,56^{\mathrm{e}}$ & $216,19 \pm 0,87^{\mathrm{a}}$ & $184,71 \pm 0,48^{\mathrm{e}}$ \\
\hline & & Etanol 50\% & $70,67 \pm 3,58^{f}$ & $213,45 \pm 0,14^{\mathrm{c}}$ & $216,48 \pm 0,72^{\mathrm{d}}$ \\
\hline \multirow{5}{*}{ Caule } & & Etanol $80 \%$ & $103,33 \pm 2,12^{\mathrm{d}}$ & $\begin{array}{l}216,24 \pm 0,79^{a} \\
1\end{array}$ & $253,77 \pm 1,80^{\mathrm{b}}$ \\
\hline & \multirow[t]{2}{*}{ Maceração } & Metanol 50\% & $6,50 \pm 2,04^{\mathrm{i}}$ & $57,73 \pm 0,41^{\mathrm{e}}$ & $63,77 \pm 1,30^{\mathrm{g}}$ \\
\hline & & Acetona $80 \%$ & $16,92 \pm 1,56^{\mathrm{g}}$ & $159,71 \pm 0,28^{f}$ & $69,08 \pm 0,65^{\mathrm{g}}$ \\
\hline & \multirow[t]{2}{*}{ Ultrassom } & Acetona $50 \%$ & $6,08 \pm 1,56^{\mathrm{i}}$ & $163,49 \pm 0,41^{\mathrm{f}}$ & $67,63 \pm 0,31^{\mathrm{g}}$ \\
\hline & & Acetona $80 \%$ & $9,83 \pm 1,56^{\mathrm{h}}$ & $157,41 \pm 0,34^{\mathrm{e}}$ & $67,83 \pm 0,48^{\mathrm{g}}$ \\
\hline
\end{tabular}

Valores foram expressos como média e desvio padrão. Letras iguais na mesma coluna indicam que as amostras não diferiram entre si $(p<0,05)$ e letras diferentes indicam que as amostras diferiram $(p>0,05)$.

\section{CONCLUSÃo}

Neste trabalho avaliou-se os teores de compostos fenólicos totais, flavonoides totais e atividade antioxidante nos extratos da casca do fruto e do caule do mandacaru obtidos com diferentes 
solventes por maceração e ultrassom. A casca do fruto demonstrou maiores teores de fenólicos totais, sendo o metanol $60 \%$ e $80 \%$ e a técnica de maceração mais eficientes para a obtenção destes compostos. Já o caule demonstrou maiores teores de flavonoides totais, sendo a maior extração em acetona $80 \%$ tanto pela técnica de maceração como por ultrassom. Em relação a atividade antioxidante, os extratos da casca do fruto demonstraram também maior potencial quando comparado aos extratos do caule. Os extratos bioativos da casca do fruto e do caule do mandacaru demonstraram potencial futura para serem explorados como fonte natural de compostos bioativos nas áreas farmacêutica, cosmética e alimentícia.

\section{AGRADECIMENTOS}

Os autores agradecem à CAPES pela bolsa de mestrado concedida ao primeiro autor.

\section{REFERÊNCIAS BIBLIOGRÁFICAS}

1. Almeida MMB, Sousa PHM, Arriaga AMC, Prado GM, Magalhães CEC, Maia GA, Lemos TLG. Bioactive compounds and antioxidant activity of fresh exotic fruits from northeastern Brazil. Food Res Intern. 2011;44(7):2155-2159, doi:10.1016/j.foodres.2011.03.051

2. Coelho EM, Viana AC, Azevedo LC Prospecção Tecnológica para o aproveitamento de resíduos industriais, com foco na indústria de processamento de manga. Cad Prospec. 2014;7(4):550-560, doi: 10.9771/s.cprosp.2014.007.056

3. Gomes VGN, Quirino ZGM, Araujo HFP. Frugivory and seed dispersal by birds in Cereus jamacaru DC. ssp. jamacaru (Cactaceae) in the Caatinga of Northeastern Brazil. Braz J Biol. 2014;74(1):32-40, doi: /10.1590/1519-6984.15312

4. Lucena CM, Carvalho TKN, Ribeiro JES, Quirino ZGM, Casas A, Lucena RFP. Conhecimento botânico tradicional sobre cactáceas no semiárido do Brasil. Gaia Sci. 2015;9:77-90.

5. Barbosa AS, Andrade AP, Pereira Júnior LR, Alcantara, RL, Medeiros BRLS, Neto MAB Estrutura populacional e espacial de Cereus jamacaru D.C em duas áreas de caatinga do agreste da Paraíba, Brasil. Ci Fl. 2017;27(1):315-324, doi: 10.5902/1980509826469.

6. Zara RF, Thomazini MH, Lenz GF. Estudo da eficiência de polímero natural extraído do cacto mandacaru (Cereus jamacaru) como auxiliar nos processos de coagulação e floculação no tratamento de água. Rev Est Amb. 2012;14(2): 75-83, doi : 10.7867/1983-1501.2012v14n2p75-83

7. Lucena CM, Lucena RFP, Costa GM, Carvalho TKN, Costa GGS, Alves RRN, Pereira DD, Ribeiro JES, Alves CAB, Quirino ZGM, Nunes EN. Use and knowledge of Cactaceae in Nostheastern Brazil. J Ethnobiol Ethnomed. 2013;9:1-23, doi: 10.1186/1746-4269-9-62

8. Dutra JCV, Ferreira JM, Pereira PRC, Oliveira J.B-H, Gervásio SV, Xavier MB, Mota MM, Luz AC, Pretti IR, França HS, Jamal CM, Batitucci MCP. Cereus jamacaru DC hydroalcoholic extract promotes anti-cytotoxic and antitumor activity. Pharmaceuticals. 2018;11(130):1-18, doi: 10.3390/ph11040130

9. Messias JB, Caraciolo MC, Oliveira IMD, Montarroyos UR, Bastos IVGA, Guerra MDO, Souza I. Avaliação dos parâmetros hematológicos e bioquímicos de ratas no segundo terço da gestação submetidas à ação de extrato metanólico de Cereus jamacaru D.C., Cactaceae. Rev Bras Farmacogn. 2010;20:478-83, doi: 10.1590/S0102-695X2010000400003.

10. Almeida AS, Santos AF. Potencial anticolinesterásico de plantas do bioma Caatinga. Diversitas J. 2018; 3:505-18, doi: 10.17648/diversitas-journal-v3i2.589

11. Neto JPS, Silva VDN, Silva PA, Santos YMP, Monteiro PHS, Silva LASG. Características físicoquímicas de frutos de mandacaru (Cereus Jamacaru P. Dc.) cultivados no sertão alagoano. Rev Craib Agroecol. 2019; 4:e7741-e44.

12. Yeddes N, Cherif JK, Guyot S, Sotin H, Ayadi MT Comparative study of antioxidant power, polyphenols, flavonoids and betacyanins of the peel and pulp of three Tunisian Opuntia forms. Antioxidants. 2013;2:37-51, doi: 10.3390/antiox2020037.

13. Renard CMGC. Extraction of bioactives from fruit and vegetables: State of the art and perspectives. LWT - Food Sci Technol. 2018;93:390-395, doi: 10.1016/j.lwt.2018.03.063

14. Soethe C, Steffens CA, Amarante CVT, Martin MS, Bortolini AJ. Qualidade, compostos fenólicos e atividade antioxidante de amoras pretas 'Tupy' e 'Guarani' armazenadas a diferentes temperaturas. Pesq Agropec Bras. 2016;51(8):950-957, doi: 0.1590/S0100-204X2016000800007

15. Bohnert KR, Mcmillan JD, Kumar A. Emerging roles of ER stress and unfolded protein response pathways in skeletal muscle health and disease. J Cell Physiol 2018;233:67-68, doi: 10.1002/jcp.25852. 
16. Kelly FJ, Fussell JC. Role of oxidative stress in cardiovascular disease outcomes following exposure to ambient air pollution. Free Radical Bio Med. 2017;110:345-367. doi: 10.1016/j.freeradbiomed.2017.06.019

17. Ismail BB, Guo M, Pu Y, Wang W, Ye X, Liu D. Valorisation of baobab (Adansonia digitata) seeds by ultrasound assisted extraction of polyphenolics. Optimisation and comparison with conventional methods. Ultrason Sonochem. 2019;52:257-267, doi: 10.1016/j.ultsonch.2018.11.023

18. Ojha S, Aznar R, O'Donnell C, Tiwari BK. Ultrasound technology for the extraction of biologically active molecules from plant, animal and marine sources. Trends Anal Chem. 2020;122:1-10, doi: 10.1016/j.trac.2019.115663

19. Khoddami A, Wilkes MA, Roberts TH. Techniques for analysis of plant phenolic compounds. Molecules. 2013;18:2328-2375, doi: 10.3390/molecules18022328.

20. Caleja C, Barros L, Prieto MA, Barreiro MF, Oliveira MBPP, Ferreira ICFR Extraction of rosmarinic acid from Melissa officinalis L. by heat-, microwave- and ultrasound- assisted extraction techniques: a comparative study through response surface analysis. Sep Purif Technol. 2017;186:297-208, doi: 10.1016/j.seppur.2017.06.029

21. Santos TRJ, Barbosa PF, Antunes HGR, Narain N, Santana LCLA. Granadilla seed extract as antimicrobial and bioactive compounds source: mathematical modelling of extraction conditions. Quality Assur Saf Crop Foods. 2019;11(2):157-170. doi: 10.3920/QAS2018.1315

22. Rezende YRRS, Nogueira JP, Narain N. Comparison and optimization of conventional and ultrasound assisted extraction for bioactive compounds and antioxidant activity from agro-industrial acerola (Malpighia emarginata DC) residue. LWT - Food Sci Technol. 2017;85:158-69, doi: 10.1016/j.lwt.2017.07.020

23. Shetty K, Curtis OF, Levin RE, Witkowsky R, Ang W. Prevention of verification associated with in vitro shoot culture of oregano (Origanum vulgare) by Pseudomonas spp. J Plant Phys. 1996;147:44751, doi: 10.1016/S0176-1617(11)82181-4.

24. Meda A, Lamien CE, Romito M, Millogo J, Nacoulma OG. Determination of the total phenolic, flavonoid and proline contents in Burkina Fasan honey, as well as their radical scavenging activity. Food Chem. 2005; 91:571-577, doi: 10.1016/j.foodchem.2004.10.006

25. Kwon YII, Vattem DA, Shetty K. Evaluation of clonal herbs of Laminaceae species against diabetes and hypertension. Asia Pac J Clin Nutr. 2006;15(1):107-118.

26. Nenadis N, Wang LF, Tsimidou M, Zhang HY. Estimation of scavenging activity of phenolic compounds using the ABTS (*+) assay. J Agri Food Chem. 2004;52:4669-74, doi: 10.1021/jf0400056.

27. Thaipong K, Boonprakob U, Crosby K, Cisneros-Zevallos L, Byrne DH. Comparison of ABTS, DPPH, FRAP, and ORAC assays for estimating antioxidant activity from guava fruit extracts. J Food Compos Anal 2006;19(6-7):669-675, doi:10.1016/j.jfca.2006.01.003

28. Abarca-Vargas R, Malacara CFP, Petricevich VL. Characterization of chemical compounds with antioxidant and cytotoxic activities in Bougainvillea $\mathrm{x}$ buttiana Holttum and Standl, (var. Rose) extracts. Antioxidants. 2016;5(45):1-11, doi: 10.3390/antiox5040045.

29. Plazzotta S, Ibarz R, Manzocco L, Martín-Belloso O. Optimizing the antioxidant biocompound recovery from peach waste extraction assisted by ultrasounds or microwaves. Ultrason Sonochem. 2019;63:1-9, doi:10.1016/j.ultsonch.2019.104954

30. Chemat F, Rombaut N, Sicaire AG, Meullemiestre A, Fabiano-Tixier AS, Abert-Vian M. Ultrasound assisted extraction of food and natural products. Mechanisms, techniques, combinations, protocols and applications. A review. Ultrason Sonochem. 2017;34:540-560, doi: 10.1016/j.ultsonch.2016.06.035

31. Calado JA, Costa FB, Pereira MMD, Nascimento AM, Formiga AS, Silva MS. Compostos fenólicos em frutos de mandacaru colhidos em dois estádios de maturação e submetidos ao hidroresfriamento. In: Dantas C de O; Silva Filho CR, Santiago Neto JF, de Medeiros JA, organizadores. Desafios da agroindústria no Brasil. II Encontro Nacional da Agroindústria; 5-8 Dez 2016; Bananeiras, Paraíba, Brasil. João Pessoa: Edição dos editors; 2016. p. 1216-1219.

32. Melo RS, Silva SM, Sousa ASB, Lima RP, Dantas AL, Dantas RL, Figueiredo VMA. Maturação e qualidade de frutos de mandacaru (Cereus jamacaru P.DC.) de diferentes bioclimas do estado da Paraíba. Rev Agrop Tecn. 2017;38(3):160-168, doi: 10.25066/agrotec.v38i3.33818

33. Moreira IS, Silva LMM, Castro DS, Lima JP, Sousa FC, Almeida FAC, Silva WP, Gomes JP, Silva CMDPS. Fruit of Mandacaru: Kinetics of Drying and Physical-Chemical Characterization. J Agri Sci. 2018;10(11):461:70, doi: 10.5539/jas.v10n11p461

34. Wit DM, Du TA, Ostoff G, Hugo A. Cactus pear antioxidants: a comparison between fruit pulp, fruit peel, fruit seeds and cladodes of eight different cactus pear cultivars (Opuntia ficus-indica and Opuntia robusta). J Food Meas Charact. 2019;7(3):1-10, doi: 10.1007/s11694-019-00154-z 
35. Silva LMR, Figueiredo EAT, Ricardo NMPS, Vieira IGP, Figueiredo RW, Brasil IM, Gomes CL Quantification of bioactive compounds in pulps and by-products of tropical fruits from Brazil. Food Chem. 2014 Jan 15;143:398-404, doi: 10.1016/j.foodchem.2013.08.001.

36. Dutra JCV, Oliveira, JB-H, Santos VS, Pereira PRS, Ferreira JM, Batitucci MCP. Fruiting increases total content of flavonoids and antiproliferative effects of Cereus jamacaru DC cladodes in sarcoma 180 cells in vitro. Asian Pac J Trop Bio. 2019;9:66-72, doi: 10.4103/2221-1691.250857

37. Moussa-Ayoub TE, El-Hady EAA, Omran HT, El-Samahy SK, Kroh LW, Rohn S. Influence of cultivar and origin on the flavonol profile of fruits and cladodes from cactus Opuntia ficus-indica. Food Res Int. 2014; 64:864-872, doi: 10.1016/j.foodres.2014.08.021

38. Andreu L, Nuncio-Jáuregui N, Carbonell-Barrachina AA, Legua P, Hernández F. Antioxidant properties and chemical characterization of Spanish Opuntia ficus-indica Mill. cladodes and fruits. J Sci Food Agric. 2018;98(4):1566-1573, doi: 10.1002/jsfa.8628. 